Using Ethnography of Communication in Organizational Research

Zoi Kalou and Eugene Sadler-Smith

Surrey Business School

University of Surrey, UK

Address for Correspondence

Eugene Sadler-Smith, Surrey Business School, University of Surrey, Guildford, GU2 7XH, UNITED KINGDOM. kalouzoi@yahoo.com; $\underline{\text { e.sadler-smith@surrey.ac.uk }}$ 


\section{Using Ethnography of Communication in Organizational Research}

\section{Introduction}

Organizations are language-mediated domains of social interaction in which communication constructs organizational realities and produces organizational phenomena (Fitch, 2001; Phillips, Sewell \& Jaynes, 2008; Tsoukas \& Vladimirou, 2001). Organizational researchers therefore require theories and methods for close-up, interpretive field studies of language and communication. A theoretical and methodological resource that can meet this need but which is currently under-used in organizational research is Hymes' (1974) Ethnography of Communication. Rooted as it is in linguistics and anthropology, Ethnography of Communication is uniquely-placed to enable organizational researchers to get closer to linguistic phenomena through deep immersion in, involvement with, and translation of human experiences of communication and interaction (see Agar, 2010; Cunliffe, 2010; Van Maanen, 1979).

We make this claim for the following reasons: first, notwithstanding significant advances made by scholars of organizational discourse, studies of organizational 'talk' based on ethnographic inquiry have been something of a rarity, so much so that ethnography has almost been de-emphasized by scholars working in this area (Phillips \& Oswick, 2012); second, scope exists in organizational research for the adoption of a coherent theory and methodology that integrates ethnographical and linguistic approaches; third, within this space, Ethnography of Communication, by focusing simultaneously on language use and matters of context, offers a lens for bringing into focus micro-level, intra-organizational, agential phenomena and macrolevel, institutional, structural, critical, and cultural issues within and across social groups; fourth, doing so militates against over emphasis on micro-features of discourse at the expense of studying socially-situated speech interactions and phenomena; fifth, Ethnography of Communication affords researchers a systematic rather than ad hoc approach for describing, 
analyzing, interpreting, and critiquing communicative events, the communicative competence of organizational actors and its consequences for behaviors and outcomes.

The long tradition of the study of 'talk' in organizations (e.g. Gronn, 1983) sits alongside distinguished ethnographic (e.g. Geertz, 1973; Van Maanen, 1979, 1988) and ethnomethodological bodies of work (e.g. Gephart, 1978). Researchers working in this domain discovered long ago that much of the everyday life of managerial work consists of "talk in interactional settings" (Gronn, 1983: 1) and therefore "favors observational strategies such as participant observation" (Gephart, 1978: 556). Indeed, many lines of organizational inquiry are inevitably 'talk-based' because understanding social activity and interaction in organizational settings is "grounded largely upon what members have to say about what such activities mean to them" (Van Maanen, 1979: 543).

Nonetheless, in spite of the 'linguistic turn' in the social sciences and organizational research (e.g. Alvesson \& Karreman, 2000a\&b; Hardy, Palmer, \& Phillips, 2000; Phillips \& Oswick, 2012; Samra-Fredericks, 2003) it is surprising that, with a few exceptions (e.g. Covaleski et al., 1998; Da Cuhna, 2013; Kornberger et al., 2011), there is a paucity of organizational ethnographies in general (Cunliffe, 2010) and in particular of ethnographic studies of language and communication in organizations. This is in spite of the fact that the "material groundedness" of ethnography shows "genuine potential" for discourse researchers (Phillips \& Oswick, 2012: 469). Furthermore, our proposal addresses two specific difficulties in organizational discourse research: first, that it has become overly concerned with language at the expense of context (Deetz, 2003); second, that the definition of context itself is problematic (Phillips \& Oswick, 2012).

In response we contemplate how Ethnography of Communication - situated uniquely at the nexus of linguistic and anthropological schools of thought - might address these and related concerns. Our contribution is to offer an introduction for organizational researchers to the theory and methods of Ethnography of Communication. Our article is structured as follows: theoretical 
and methodological backgrounds; Ethnography of Communication; methodological notes and illustrative example; conclusion.

\section{Theoretical Background}

In this section we: position Ethnography of Communication in relation to the broader ethnographic frame of reference; probe more deeply into its relationship with linguistics and sociolinguistics; compare Ethnography of Communication to a number of related approaches for the study of conversation and interaction.

\section{Ethnography and Ethnography of Communication}

When first proposed by Dell H. Hymes (1927-2009) over half a century ago, Ethnography of Communication, which is also known as 'Ethnography of Speaking' (Gumperz \& Hymes, 1972; Hymes, 1962, 1964a,b, 1972, 1974, 1986), was considered a novel approach for researching language because it sought to study the linguistic practices of sociocultural groups by paying particular attention to matters of context (Keating, 2001). Its antecedents were in the anthropological and ethnographic traditions of Franz Boas and Bronisław Malinowski ${ }^{1}$ founded on the precept that context is "fundamental in understanding speech" (Keating, 2001: 286).

Ethnography more broadly is concerned with the study of social interactions and culture from the perspective of naturalism, within humanistic, hermeneutic, and interpretivist paradigms (Berg, 2007; Van Maanen, 2006). Its empirical aims are to capture and make sense of the perspectives and practices of people 'in vivo'. Ethnographic researchers immerse themselves in the setting and collect data directly and systematically by participating, watching, and listening attentively (Berg, 2007; Brewer, 2004). The essence of ethnography is an endeavor to represent "the social reality of others" (Van Maanen, 1988: xiii) in terms of interactions, artefacts, actions, symbols, and language of organizational members (Cunliffe, 2010). A particular challenge faced by ethnographers is the sheer number of activities and interactions they may witness; they must learn therefore to watch and listen skillfully (Berg, 2007: 192). Focusing attention upon 
theoretically and linguistically significant features of structure and context may prove helpful (Keating, 2001); but how might the potential salience of the plethora of available features be determined? Ethnography of Communication affords researchers a solution to this problem.

Hymes' Ethnography of Communication (Hymes, 1974) provides a system for the collection and collation of data by means of observational strategies and field-noted records configured in terms of number of theoretically coherent dimensions of the communicative situations and events to be studied. Practised skillfully and executed effectively the ethnographic approach yields close-up accounts of life as lived by "particular people, in particular places, doing particular things, at particular times" (Van Maanen, 2006: 17). Such accounts are derived iteratively and recursively (Agar, 2010) and the texts which ethnographers create afford stories and 'cultural codings' (Goodall, 2010) that would be hard to achieve by any other means. As far as understanding organizational talk is concerned, the ethnographic approach offers the potential for an appreciation of the reciprocity of the dual relationship between language use and social organization (Saville-Troike, 2003).

Ethnography of Communication captures language use in a way that is faithful to the spirit of ethnographical inquiry; it endeavors to yield contextual and "conceptual richness" in its narrative accounts (Sherry, 1988: 544). Ethnography of Communication connects ethnography (the description and analysis of culture) with linguistics (the description and analysis of language) (Smart, 2012). It provides "a perspective on language as intrinsically tied to context and human activity" (Blommaert, 2005: 233) from the viewpoint of the members of speech communities, that is "groups of people who share at least one valued way of speaking, and interpretive resources within which that way of speaking is located" (Fitch, 2001: 57). Ethnographers of communication aim to "discern patterns proper to speech activity [in] contexts of situation" and which are separate from the more general frames of reference (e.g. religion) with which ethnographers are primarily concerned (Hymes, 1974: 3). 


\section{Linguistics, Sociolinguistics, and Ethnography of Communication}

Linguistics as a discipline encompasses an array of subfields concerned with the scientific study of language. The key historical figures Boas, Sapir and Whorf laid the groundwork for the development both of sociolinguistics and Hymes' Ethnography of Communication (Hymes, 1974). Sociolinguistics developed out of structural linguistics, Whorfian linguistic relativity, and the American anthropological tradition. In the early decades of the last century Edward Sapir (1884-1939) and his student Benjamin Whorf (1897-1941) theorized that language is not only influenced by our perception of the world but also determines our perception of the world. The lineage of this relativistic movement in linguistics traces back to Franz Boas (1858-1942), the 'father of American anthropology', in that Sapir was one of his students. A corollary of 'linguistic relativity' (cf. the Sapir-Whorf hypothesis ${ }^{2}$ ) is that members of different cultures or communities interpret the world differently, according to their cultural-linguistic foundations: "Language and our thought-grooves are inextricably inter-related, are, in a sense one and the same" (Sapir, 1921: 217 cited in Fitch, 2001: 58).

Whorf considered culture to be a linguistically-conditioned microcosm where conceptions of the world are reflected in language and not only reveal but also shape perception. Whorfian linguistic relativity constitutes the bold claim that it is through language that cultures affect ways in which members of a community think, classify, and make sense of experiences of the world (Gumperz \& Levinson, 1996). These insights influenced not only conceptions of the nature of language and its place in human culture but also foregrounded the necessity of taking account of the role context plays in discourse.

As a scientific discipline, sociolinguistics' foundations ${ }^{3}$ embrace two fundamental precepts: first, language is organized not only in terms of grammar but also as part of the communicative conduct of a community; second, study of language-in-use must be a multidisciplinary endeavor drawing on linguistics, anthropology, and sociology (Hymes, 1974: vii-viii). Hymes, along with his colleague John J. Gumperz (1922-2013), is acknowledged as the pioneering figure in this 
field (Duranti, 1985; Rampton 2009). However, whilst both sociolinguistics and the

Ethnography of Communication are concerned with the discovery of regularities in language use, sociolinguists typically focus on grammatical and pronunciation variability, whereas ethnographers of communication are concerned with how communicative units are organized, how they pattern in 'ways of speaking', and how these patterns interrelate with other aspects of culture to derive meaning (Saville-Troike, 2003).

Hymes is also important in that he was instrumental in carving-out a space for the study of language that escaped the limitations of the Chomskyian paradigm. Hymes considered the Chomskyian a priori 'mental grammar' to have failed to account for the enormous variety in and socially contextualized ways of language use, not least the social appropriateness of some ungrammatical utterances and the social inappropriateness of some grammatical utterances (Johnstone \& Marcellino, 2010: 3). Hymes thereby challenged the Chomskyian view of the innateness of language and its implications for linguistic competence (Saville-Troike, 2003: 18). More particularly, Chomsky emphasized the notion of a universal grammar and the belief that language - analogous to a Cartesian conception of the mind - is separated from the body and from anything bodily, such as feeling, emotion, imagination, and perception (Lakoff \& Johnson, 1999). Chomsky's claim is that language is a matter of abstract symbols, and having nothing to do with what the symbols mean, how they are used to communicate, or any other aspect of human experience, cultural or personal.

The Chomskyian stance is at odds with precepts of the pioneers of linguistics Saussure ${ }^{4}$, Boas, Sapir, and Whorf and their views on the relationship between language and mind (Lakoff \& Johnson, 1999) ${ }^{5}$. In keeping with this latter tradition, Hymes foregrounded the study of language use rather than the language system and emphasised the need to analyse language use in relation to participants' perspectives and their situated and culturally-constituted experience (Maybin \& Tusting, 2011). The Hymesian notion of "communicative competence", denoting that knowledge beyond the grammatical rules is required in order to communicate, cf. Chomskyian 'linguistic 
competence', is used to describe how an individual participates in society not only as a speaking member, but also as a communicating member, that is as someone who is able to participate in a community and understand what is shared and meaningful. Hence, Ethnography of

Communication focuses on the integration of linguistic function and form in the description and analysis of speaking (Saville-Troike, 2003) rather than upon structure and linguistic form in isolation (Blommaert, 2009b, Rampton, 2009).

Hymes' project was a bold one: for him sociolinguistics also constituted a 'science of the people', democratic and anti-hegemonic, abstaining from "pontificating and a priori theorizing, offer[ing] a voice to those it studied" (Blommaert, 2009a: 258). It was a means of understanding the role of language in inequality and challenging inequalities (Hornberger, 2009), and anticipated later developments in critical discourse research (see below). By addressing issues of language socialization, function and context, Hymes was able to articulate an ethically-, politically- and ethnographically-rooted vision of an 'anthropology of language' (Blommaert, 2009a\&b; Collins, 2009; Ervin-Tripp, 2009). Hymes' magnum opus is his Foundations in Sociolinguistics (1974). The edited volume with Gumperz Directions in Sociolinguistics: The Ethnography of Communication (1986) is an extensive and authoritative text which maps-out the domain for specialists and non-specialists alike.

\section{Related Approaches: Conversation Analysis, Critical Discourse Analysis, and} Ethnomethodology

The study of conversation and interaction is an increasingly important research topic in the social sciences in fields as varied as linguistics, sociology, anthropology, communication studies, psychology, and organization studies (Gordon, 2011). Readers are referred to Schiffrin, Tannenn and Hamilton (2003) and the two handbooks of Wetherell, Taylor and Yates (2001a\&b) for a comprehensive treatment of the field. In what follows we will offer a brief summary of several relevant approaches and highlight principal differences between them and Ethnography of Communication, see Table 1. 
Conversation Analysis: Conversation analysis (Sacks, 1992, and classified with 'Interactional Linguistics' by Wetherell and colleagues) scrutinizes the norms governing sequential interactions between speakers in 'segments of talk' (Heritage, 2001) from which patterns, such as the 'normative orders' transgressed deliberately in Garfinkel's 'breaching experiments', may be anticipated and discerned by a researcher whose role is "detached observer" occupying an analytically-driven rather than theoretically-led approach (Taylor, 2001: 312). Conversation analysis is a mode of micro-sociological inquiry (Scott \& Marshall, 2005) used to interpret discourse and social interaction through the analysis of transcribed verbal interactions (Heller, 2003; Lynch \& Peyrot, 1992; Sacks, 1992). Conversation analysts focus on aspects of context referred to by speakers themselves; it is therefore circumscribed in its appreciation for context.

Interactional sociolinguistics, which Wetherell et al. (2001a\&b) categorized with conversation analysis, is most often associated with the work of Hymes' close colleague the anthropological linguist John Gumperz. At the heart of interactional sociolinguistics is the notion of the 'contextualisation cues' used by participants to index or signal an aspect of the situational context and provide interlocutors with recognisable markers for interpreting contextual presuppositions (Hall, 2012). Any misinterpretation or misuse of cues and any consequent miscommunication is assumed to be due to a lack of shared knowledge and understanding of the meanings of specific cues (Hall, 2012).

Whilst the above are not unconnected to our focal interest, Ethnographers of Communication frame their analyses in terms of the wider cultural context in order to interpret specific instances of dialogue (Maybin \& Tusting, 2011). Ethnographic foci and procedures are most useful for this type of conversational inference since they offer a macro-description of community structure and illuminate the nature and significance of context in language use and the functions of language in society (Blackledge, 2012; Saville-Troike, 2003). Ethnography of Communication, by focusing on the study of language and context in field settings, affords organizational 
researchers an approach which transcends the micro-level of analysis of linguistic form and code instantiated in some aspects of interactional linguistics and the study of transcribed talk.

Critical Discourse Analysis: Critical Discourse Analysis is part of the wider landscape of critical approaches to language and society (Blommaert, 2005). It differs from other approaches for socially contextualised language research in that it is a socially committed activity with an acknowledged political, ideological and ethical stance, seeing discourse as performed within structures of power and domination (Saville-Troike 2003). Critical Discourse Analysis is an approach to discourse analysis within an ethnographic framework (Atkinson, 2011) but proceeds from the assumption that discourse is an element of social practice which is socially constitutive and socially conditioned (see: Blommaert \& Bulcaen, 2000; Chouliaraki \& Fairclough, 1999; Fairclough, 1992). Critical Discourse Analysis assigns a central role to language in social phenomena that are constituted within political, ideological, and ethical arenas (Fairclough, 1992). Critical Discourse Analysis's motivations resonate with those of Hymes (Rampton, 2004) because language's potential to create and maintain power constitutes an important topic for Ethnographers of Communication (Saville-Troike, 2003).

Critical Discourse Analysis and Ethnography of Communication are potentially compatible, or at least complementary approaches to the study of language but one important difference lies in the fact that Ethnography of Communication favours bottom-up accounts of communicative phenomena and sees language not only as permeable to social situations and roles, but also as helping to define them (Duranti, 1997), whilst Critical Discourse Analysis presupposes a particular social theory to explain communicative behaviour (Saville-Troike, 2003). Nonetheless Hymes' Ethnography of Communication may be seen as a democratic and anti-Hegemonic project; it was for him a science of the people, abstaining from "pontificating and a priori theorizing but instead offer a voice to those it studied" (Blommaert, 2009b: 258).

Ethnomethodology: Garfinkel (1986) defined ethnomethodologies as "various policies, methods, results, risks, and lunacies with which to locate and accomplish the study of the 
rational properties of practical actions as contingent ongoing accomplishments of organized, artful practices of everyday life" (p.309). Ethnomethodology is mainly concerned with discovering the underlying processes which speakers utilize in order to produce and interpret communicative experiences. In this respect, ethnomethodological researchers study the methods people use to create social order, including language use and the unstated assumptions which govern its use and interpretation (Saville-Troike, 2003) with the aim of understanding how individuals make ordinary, everyday, practical sociological reasoning analyzable (Garfinkel, 1974). Ethnomethodology has not been uncontroversial (Scott \& Marshall, 2005), nor is it a single coherent approach; instead it relies to varying degrees on contributions from various subfields including social psychology and interpretive sociology (Lynch \& Peyrot, 1992).

The ethnomethodological approach connects broadly with the remit of Ethnography of Communication since amongst its concerns are discovering structure in methods of speech, and seeing verbal interactions as context-specific "artful accomplishment” (Gumperz \& Hymes, 1986: 28). However, Pollner and Emerson (2001) draw attention to the fact that the relationship between ethnomethodology and ethnography has not always been a congenial one, and point out various tensions and incommensurabilities between the two approaches that are the subject of on-going debates. For example, ethnomethodologists caution that ethnographers do not go "far or deep enough" and, whilst the latter can never "recover the lived order" in the way that ethnomethodologists might, ethnography on the other hand maintains a "commitment to sociology" (Pollner \& Emerson, 2001: 130).

\section{[TABLE 1 HERE]}

\section{The Methodology of Ethnography of Communication}

A principle of Hymes' Ethnography of Communication is that studying language and discourse cannot take linguistic form, code or speech as its only frame of reference since language is first and foremost a socially-situated cultural form (Saville-Troike, 2003). Rather, it must investigate "communicative habits as a whole" taking community-as-context. A corollary 
of this is that it is ethnography rather than linguistics and communication rather than language that constitute its basic architecture (Hymes, 1964a: 3). Ethnography of Communication's focus is the immediate situated and interactive context of language use and its local accomplishments wherein speech, social meanings, and local context intertwine, creating 'patternings' or normative structures derived from local ways of speaking (Saville-Troike, 2003). As such it can help to explain diversity in human communicative behaviors (Johnstone \& Marcellino, 2010) and account for what is permissible as contextually appropriate and inappropriate communicative behavior in a given social group (Saville-Troike, 2003).

It would be a mistake to see Ethnography of Communication purely as an ethnographic method: Hymes' ethnography "can and should be seen" as a complete intellectual program, involving language and communication, and including ontology and epistemology, "both of which are of significance for the study of language in society, or better, of language as well as of society" (Blommaert, 2009a: 261 original emphases). Hymes was well aware of the challenges to be faced when he acknowledged that: "The most novel and difficult contribution of sociolinguistic description must be to identify the rules, patterns, purposes, and consequences of language use and to account for their interrelations" (Hymes, 1974: 75). Because such patterns are often tacit and part of social actors' 'practical consciousness' (Giddens, 2013), their systematic study potentiates access to unconscious or implicit cultural patterns that would otherwise be opaque to researchers (Sherzer, 1987: 295).

The method of Ethnography of Communication brings into sharper relief tacit signalings used by participants in communicative events enabling researchers to decode the meanings implicit in interactions in speech communities. Hymes himself argued that for a person to participate in a speech community does not imply that he or she is member of it; similarly, a person or group might also belong to more than one speech community (Hymes, 1974). However, a person who is member of a speech community does not only know the language of the community but also what to say. In this respect, speech communities cannot be defined only based on the language 
used, but also on a variety of other criteria such as behavior, relations to other members and shared knowledge, the analysis of which - as Hymes acknowledged - is a complex task.

Moreover, what constitutes appropriate language use in a speech community can legitimate or de-legitimate the language practices of certain members of social groups (Keating, 2001). Anticipating later approaches such as Critical Discourse Analysis (Fairclough, 1995, see above), Hymes' Ethnography of Communication is imbued with a critical element commensurate with aiming to understand legitimizing/de-legitimizing, implicit/explicit forces, and uncover and challenges inequalities ${ }^{6}$. By way of further elaboration we now define and explain Hymes' “signature set” of concepts (Rampton, 2009: 359), namely: ‘communicative competence'; 'speech events'; 'SPEAKING grid'.

\section{Communicative Competence}

'Communicative competence' is the capability to not only know the language code, for example its rules of grammar, but also know "what to say to whom, and how to say it appropriately in any given situation" based on the "social and cultural knowledge speakers are presumed to have which enables them to use and interpret linguistic forms" (Saville-Troike, 2003: 18). Instantiated in the notion of communicative competence is not only 'what' speakers need to know to communicate appropriately in a speech community, such as appropriateness, occurrence, and feasibility of utterances, but also 'how' competence is acquired (Keating, 2001; Saville-Troike, 2003).

Communicative competence is relevant for organizational discourse research because: (1) the study of language in organizations ought to concern itself with elements or 'markers' that must be attended to in describing, analyzing, and interpreting the abilities of speakers to use language for everyday communication (Duranti, 1985; Keating, 2001); (2) communicative competence is more than just speech: members of a speech community, and for that matter researchers, must be able to identify and discriminate between markers that carry meaning and markers that are insignificant, furthermore to focus exclusively on oral channels is likely to yield too narrow an account (Saville-Troike, 2003); (3) communicative competence implicates shared knowledge 
amongst members of the speech community not only of linguistic code but also "rules, norms and values which guide the conduct and interpretation of speech" (Farah, 1998: 125). This bears some similarities to 'communities of practice' (see Lave \& Wenger, 1991) in which individuals' appropriation of the language of the community can be "a vehicle for denying negotiability and can thus result in non-participation" (Wenger, 1998: 203).

Communicative competence encompasses linguistic and cultural knowledge, and interaction skills which, in combination, enable communicatively competent speakers to know, for example, to whom they may or may not speak, when to speak and when to not do so, how to talk to different persons, what counts as appropriate verbal and non-verbal behavior, what the routines for turn-taking are, and so forth (Saville-Troike, 2003). For example, in a Top Management Team meeting a communicatively competent CEO's personal assistant knows when he or she may or may not speak, what may be said, and how he or she may or may say it. Such patternings, embedded as they are within a more general cultural competence, may vary not only between organizational cultures but also within organizational sub-cultures.

\section{Speech Events}

Ethnography of Communication's over-arching social unit is 'speech community'. Within this Hymes distinguished three nested units of analysis: 'speech situation', 'speech event', and 'speech act' (or 'communicative situation', 'communicative event' and 'communicative act'). These are fundamental taxonomical elements for describing and analyzing communication within a speech community. Speech events consist of "one or more strips of social interaction" (Duranti, 1985: 203) distinguishable as "brief, self-contained sequences with readily identifiable beginning and end" (Saville-Troike, 2003: 110). The SPEAKING grid provides an etic (general or abstract) framework for emic (specific) description, analysis and interpretation (Duranti, 1985; Fitch, 2001) of the local use of language (Keating, 2001). It facilitates the systematic compiling of a structured inventory of a community's speech practices and enables comparisons to be made across speech settings (Keating, 2001; Sherry, 1988). 
The following example illustrates these units. A conference presentation is a speech situation within the speech community of a particular professional group and might include the following speech events: 'small talk' amongst participants; calling to order by the chairperson; introduction of presenters; presentation; question-and-answer; closing remarks and thanks; informal small talk between participants and off-line questions to presenters. The situation involves a single set of participants, for example the chairperson, speakers, and audience; the setting remains the same throughout, and events and transitions are signaled by different forms of speaking and different rules of interaction. Within a specific speech event, such as 'presentation', there tends to be a typical sequence of communicative acts for example change in body position by the chairperson standing-up, use of artefacts by the speaker opening a PowerPoint presentation, change in rules for interaction by inviting questions, the signaling of proximity of the end of the event by the chairperson's exaggerated look at her watch. How a communicative act is interpreted by participants will be culture-specific; for example a person, such as the chairperson, standing-up need not have any absolute or universal communicative significance.

\section{The SPEAKING Grid}

Field procedures for the procurement of ethnographic data should be "grounded in the investigation of communication in natural contexts" (Saville-Troike, 2003: 95). Hymes' devised the so-called 'SPEAKING grid' for the systematic compiling of a structured inventory of a community's speech practices and so that comparisons can be made within and across speech settings (Keating, 2001; Sherry, 1988). The grid draws explicitly on earlier work by the RussianAmerican linguist Roman Jakobson (1896-1982) who also influenced Claude Lévi-Strauss and Roland Barthes (see Jakobson, 1960). Hymes expanded Jakobson's model of the speech event (1960), which elaborated and identified the components that play an important role in the communication process (Hymes, 1974). The SPEAKING grid enables the specification of the content and context of speech, affords researchers an analytical tool for "situated and purposive" description and interpretation of communication (Hymes, 1974: 106), and provides an etic 
framework from which an emic account may be built (Keating, 2001; Saville-Troike, 2003). Hymes happened to make the components of his framework mnemonically convenient by grouping them together in relation to eight letters, S-P-E-A-K-I-N-G (Duranti, 1985) ${ }^{7}$. Certain components can be sub-divided, and researchers have added minor variants to Hymes' original scheme (e.g. Saville-Troike, 2003), see Table 2. The elements of the grid are described below.

\section{[TABLE 2 HERE]}

\section{Situation: 'Setting' and 'Scene' of the event}

'Setting' and 'Scene' map onto and circumscribe the taxonomic unit of 'Speech Situation'. The latter provides a means for evaluating appropriateness of speech acts and determining what is permissible and/or appropriate in a given setting (for example in a board room versus in an elevator) or scene (for example during a sales pitch versus during a press interview) but not in others (Hymes, 1974; Fitch, 2001). Situations are also likely to be differentiated by spatiality and temporality, manifested as participants' positions as they move through a setting, and the significance of who can or is 'allowed' to be where and when (Keating, 2001). In designating and delineating situation the researcher documents: 'Setting', physical (for example spatio-temporal) aspects of the situation which are important in understanding the meaning of the event (for example 'Check-in desk at Chicago O'Hare' or 'Conference arena'); 'Scene', analogous to 'setting the scene' of an action and documented in terms of the 'psychological setting' or cultural definition of the event (for example 'international business trip' or 'shareholder meeting') (Duranti, 1985; Keating, 2001). In terms of how to use the grid, sample questions for the descriptive analysis of situation might include: (1) What does the setting look like, what is the time of day, what is the physical arrangement of artefacts? How do participants organize themselves spatially/temporally?

(2) What is the cultural definition/significance of the occasion? (Saville-Troike, 2003).

\section{Participants: speaker / sender / addressor / audience / hearer / receiver / addressee}

'Participants' includes not only those who participate actively or directly in the communicative event, but also those who may be absent but are in some way involved in the communication 
processes. Hymes expanded participants in this way because other stakeholders may have explicit or implicit roles to be acknowledged in understanding a particular strip of action. Failure to recognize or take account of implicit roles may obscure important interactions. For example, a CEO's speech at an Annual General Meeting to hearers who occupy the same setting may also be addressed to a wider audience of politicians, press, and public. Absent shareholders and their interests may have, or confer, a tacit presence in a board meeting. Similarly middle managers and other employees of an organization, even if physically absent, may nonetheless be considered participants in their capacity as recipients of the outcomes of senior managers' communicative acts. Roles may also be proxies, for example a CEO's press officer participating in a speech situation such as a press conference to announce a firm's full-year financial results is a professional orator speaking on behalf of an absent speaker, the CEO.

In specifying participants the researcher must identify not only those individuals in the speech community who are participating the speech event but also consider going beyond conventional speaker/hearer dyads to a more complex network of associations and interactions representing subtler distinctions, i.e. speaker, addressor, addressee, hearer, receiver, or audience (Duranti, 1985; Hymes, 1974; Saville-Troike, 2003). Failure to identify participants accurately or completely may impede the researcher's ability to adequately describe linguistic and communicative features of speech events (Duranti, 1985). Sample questions for the descriptive analysis of participants might include: (1) Who (present or absent) is taking part in the event (age, gender, ethnicity, etc.)? (2) What is the observed/actual hierarchy of authority? (3) What are participants' roles/responsibilities, rights/obligations, attitudes/expectations, etc.? (SavilleTroike, 2003).

\section{Ends: purposes of speech event, expected goals and actual outcomes}

'Ends' concerns not only the purposes of participants engaged directly in the event but also may embrace wider system or societal goals (Duranti, 1985): “[the] purpose of an event from a community standpoint, of course, need not be identical to the purposes of those engaged in it" 
(Hymes, 1974: 57). Purposiveness of communication (encapsulated in Ends) differentiates it from interaction more generally (Keating, 2001); purposiveness may also change during the course of an event, for example if it is apparent that a hearer is not attending to the message content (Duranti, 1985). The researcher should be open to considering differing and distinct ends for different participants, be alert to their various motives and intentions, and to the dynamics that influence the outcome of a communicative event. Sample questions for the descriptive analysis of ends might include: (1) What is the event about and why is it happening? What goals are participants endeavoring to achieve? (2) What outcomes did the participants actually achieve? (Saville-Troike, 2003).

\section{Act sequence: message form and content}

Act sequence in a speech event has a number of interdependent components. Act sequence concerns "information about the ordering of communication acts within an event" (Saville-Troike (2003, p.122), it is referred to by Duranti (1985) as the event's "sequential organization" (p.212). Ordering is rigid in ritual events, such as greeting, answering the phone, making a commercial pitch, and less so in conversation (Saville-Troike, 2003). Transgression of sequential organization, for example speaking out of turn, may indicate lack of communicative competence.

Hymes' (1974) exposition of the grid emphasized 'message form' and 'message content' in act sequence since 'how' and 'what' contribute inter-dependently to meaning. Saville-Troike (2003) schematizes message form in terms of 'channel', that is 'vocal' such as spoken language versus 'non-vocal' such as written text, and 'code', that is 'verbal' such as spoken language versus 'non-verbal' such as paralinguistic or prosodic features of speech as in laughter or intonation. For example, in an email or text message the non-verbal visual symbol “;-)" may confer a specific meaning such as irony by depicting a 'wink' (see Saville-Troike, 2003: 116). Silence, that is non-verbal channel and non-vocal code, may convey propositional content, for example a 'stony silence' in response to an autocratic leader's invitation for questions at the end of a presentation or speech may indicate covert dissatisfaction or tacit resistance. 
'Message content' indicates substantive and referential content of what is being communicated (Saville-Troike, 2003). As noted, a principle of Hymes' framework is that how something is said (the message's form) is part of what is said (the message's content) (Hymes, 1974: 54). For example, a sentence in interrogative form may be a request, command, or statement depending on a variety of speech parameters and contextual factors, for example manner and social relationships. A boss who asks a secretary: "Is the toner in the printer finished?" possibly requests, or more likely orders, a changing of the printer's toner cartridge. These are indirect speech acts, and are often used as a politeness feature but may also denote or appropriate power and signal or command acquiescence.

In practice, message form and message content are inter-twined and rely on participants' communicative competence for their disentanglement and effective interpretation in context (Hymes, 1974). For example, to answer only 'yes' in response to the question 'have you got a cigarette?' without offering a cigarette will likely indicate lack of communicative competence in certain cultural settings. In field settings ethnographers of communication should not be overlyconcerned if message form and message content prove difficult to separate analytically since in communicative practice they are "tightly interdependent" (Hymes, 1974: 55). Sample questions for the descriptive analysis of act might include: (1) Is there a sequential ordering of speech acts, if so what is it? (2) What channels (vocal, non-vocal) and codes (verbal/non-verbal) are in use? (3) What is the message content of a given speech act (Saville-Troike, 2003).

\section{Key: tone, manner, or spirit of speech acts}

'Key' is the tone, manner, or spirit in which speech acts are accomplished and which impart and provide cues on interpretation (Duranti, 1985). A speech act in a 'mock' versus 'serious' key performed in the same setting with the same participants would likely signal quite different readings (Keating, 2001). When key is in "conflict with the overt content of an act, it [key] often overrides the latter [content]" (Hymes, 1974: 58). If a senior manager complements a team on its performance in a sarcastic key the sarcasm over-rides the form and literal content of the message 
signaling not only different message content but also may be indicative of the relationship between speaker and message recipients.

Researchers must be alert to the fact that variations in key can be achieved both verbally (for example choice of language or dialect), nonverbally (for example through style of dress, facial expressions, gestures, posture, and intentional silence), and through paralinguistic and suprasegmental phonetic features (for example intonation, volume, stress of voice, and coughing), see 'channel' and 'code' above. Noise-making without words may be an intentional way of communication, as in the case of coughing used to signal warning, sanction, or surprise; similarly a smile may have different meanings to different people in the same context. The features of key are apt to shift from moment-to-moment and from context-to-context but their systematic observation, recording, and documentation constitute a vital element of the analysis (Hymes, 1974). A sample question for the descriptive analysis of key might be: What is the tone, manner, or spirit in which the speech act is performed? (Saville-Troike, 2003).

Instrumentalities: channel /medium of transmission of speech and forms of speech /speech style 'Instrumentalities' covers the context-specific linguistic resources available for a given speech event and in a speech style selected from available alternatives in relation to the event's purpose (Hymes, 1974). Researchers' attention should focus on the means or agencies of speaking, comprised of physical medium of transmission of message (for example, oral, written, telegraphic, electronic or other medium) and related 'forms of speech' such as varieties of a language including dialect and speech styles, and aspects of speech or idioms unique to particular situations, genres or persons. It is also important that, where relevant, phonological registers are captured. For example, the appropriate phonological register for a CEO's formal speech to shareholders read from an autocue would be wholly inappropriate for a media interview on a TV chat show. Also, particular forms of speech might be associated with certain organizational settings or cultures, for example company-specific 'office jargon' as well as particular styles associated with 'management speak' such as the over-use of the phrase 'win-win' in conflict management (McNary, 2003). 
Sample questions for the descriptive analysis of instrumentalities might include: (1) What linguistic resources are available? (2) What are the styles of speaking? (Saville-Troike, 2003).

\section{Norms: rules of interaction and interpretation}

These include the protocols of interaction with reference to the way participants 'should' act and speak in terms of interruptions, silence, turn-taking and so forth based on local or cultural conventions, and the norms of interpretation, that is the common rules or standards of a speech community that constitute an interpretive frame based on mutual knowledge and shared cultural pre-suppositions (Hymes, 1974; Saville-Troike, 2003).

Whilst rules of interaction comprise rules for use of speech including non-verbal behaviors, norms of interpretation provide other information pertaining to deeper meanings conveyed. They may designate specific behaviors permitted (for example proximity and physical contact) as well as patterns which themselves may be subject to differing interpretations (for example use of silence for indicating opposition or agreement) (Blackman \& Sadler-Smith, 2009; SavilleTroike, 2003).

Researchers should be alert to the fact that rules for interaction may also be culturallycodified in the form of aphorisms or proverbs, for example 'don't speak until you're spoken to'. These reflect social and ritual contexts and manifest in rules of verbal etiquette to be observed when meeting a senior business, state or religious figure for example. In the organizational domain some participants in a meeting have a clear mandate to speak and act, whilst others are unheard, invisible, or do not warrant a voice. A norm of interaction might be that it is unacceptable to interrupt a CEO's speech, or considered protocol that s/he speaks first. As far as norms of interpretation are concerned, a CEO's presence in a meeting, for example the fact that s/he 'turned up', may have significance beyond their mere presence thereby (re-) structuring dispositions of the community. Attending to the norms of interaction and norms of interpretation are an important means by which researchers may unearth deeper structures underlying participants' speech acts. Sample questions for the descriptive analysis of norms might include: 
(1) What are the rules that govern speaking for the event? (2) What are the standards of speech, how are breaches evaluated, what are the sanctions for doing so? (Saville-Troike, 2003).

Genres: textual categories - the type of the event

'Genres' allows researchers to identify the various categories of speech used such as "poem, myth, tale, proverb, riddle, curse, lecture, commercial, etc.” (Hymes, 1974: 61). For organizational researchers typical genres might include PowerPoint presentation, sales pitch, etc. but this is by no means an exhaustive list. In capturing genres researchers need to be alert to the fact that genres may also be embedded to each other, as for example a presentation that takes place in a lecture and in certain genre, for example sales pitching and PowerPoint presentation, may be contained within a corresponding speech situation, in these cases market pitch and management training course. Setting and its genre can be intertwined in that there are a limited number of settings in which any genre could be appropriate (Saville-Troike, 2003). In spite of this embeddedness, Hymes (1974) maintained that genres should be treated independently from events and settings for the purposes of analysis, since they may occur in (or as) different events, for example the genre of a PowerPoint presentation is as likely to occur in a training course as it is in a sales pitch. A sample question for genre might be: What is the type of event? (Saville-Troike, 2003).

\section{Conducting Ethnography of Communication and an Illustrative Example}

Hymes' SPEAKING grid enables the ethnographic description and interpretation of human purposes in language (Johnstone \& Marcellino, 2010) but its use comes with two provisos: first, the grid only happens to be mnemonically convenient, the mnemonic itself does not have any formal significance, theoretical role, or ethnocentric bias (Hymes, 1974); second, use of the grid is not the culmination of the research process, rather it is a stage in the systematic process of describing, interpreting, and theorizing speech situations, events, and acts. In what follows we outline the steps involved in conducting an Ethnography of Communication and then further illustrate this with our own example of the grid's use. 


\section{Conducting Ethnography of Communication}

The initial task for an organizational researcher in using Ethnography of Communication is the formulation of possible research questions and the identification of the speech community to be studied (Saville-Troike, 2003). Such questions might be related theoretically to observable sociocultural phenomena, for example 'how is organizational power enacted communicatively?' and embracing the relationship of power to patterns of communication and participants' communicative competence, how structures of authority arise from the communicative actions of people, and how these communicative actions are shaped reciprocally by the context. In the illustrative example that follows we take commercial meetings as the 'speech community' of investigation, and then formulate provisional questions based on the norms of interaction and interpretation within this community, how participants' role dynamics are reflected in their utterances and the style of speaking, how ritualized these events are, what the significance is of the specific situational parameters, what they tell us about the dynamics and structures of power and authority and how these inter-relationships might affect the outcome of a meeting. In order not to be overwhelmed, the researcher will naturally orient the focus of her analysis to the phenomenon of interest; the SPEAKING grid is helpful in that it allows the segmenting of aspects of context in which the phenomenon of interest is enacted (Schiffrin, 1994). We have adopted and adapted the questions enumerated by Saville-Troike (2003: 110-124) as a useful guide for data collection in relation to each of the grid's components and sub-components and summarized them in Table 3.

\section{[TABLE 3 HERE]}

The analyst will often 'chunk' an observed strip of action into textual units, that is separate speech acts; this is not only methodologically convenient for the analyst, it is also likely to reveal how speakers naturally divide their speaking into parts which reflect phases in a temporallyordered sequence, and this provides an important lead "in finding [the] 'emic' ways of narrative structuring" (Blommaert \& Dong, 2010: 74). This constitutes the backbone of the descriptive 
analysis; however the researcher is not only required to trace which of these components are relevant within the particular speech community, but also to ask bigger questions about how each component relates to all of the others (Saville-Troike, 2003). For instance, what is the relationship between the settings and the purposes of the speech event and how does each affect the other? What are the different purposes of the participants and how do these purposes manifest in speaking, and what do they tell us about the substantive issue of the research, for example power and authority? Likewise, at a more fine-grained level: what is the relationship between the key of the interaction and the ends of the different participants? A joke, for example, at the beginning of the meeting may signal an effort to 'break the ice', a means for establishing power, or 'to test the waters' in pursuit of some other, as yet obscure, goal. A speech act can serve different purposes and has significance depending on the other situational parameters instantiated in the components of the SPEAKING grid. This brings us to a crucial point in relation to doing an Ethnography of Communication: analyzing a speech event as a whole, rather than as a collection of discrete components (which will only take the researcher as far as a fairly superficial analysis), is a precursor to uncovering higher-order abstractions, generalizations, and theorizations.

The meticulous tracing of the interrelationship of components may allow salient aspects of the event and deeper structural attributes of the speech community to be unearthed, meaningful nuances to be discovered and described, and most importantly allow the researcher to reach an informed interpretation of what she has witnessed. It is at the interpretative stage that the meaning of the communicative event will start to take shape in a context of "specific social relations, interactional histories and institutional regimes, produced and construed by agents with expectations and repertoires that have to be grasped" (Rampton et al., 2014: 3). At this point the researcher is likely to be guided by, or need to remind herself of, the overall aim of the study since it is possible to become deeply immersed in the minutiae of the description. 
The 'descriptive analysis' which moves from 'parts' to 'whole' represents the first stage in a process for the investigation of communicative events; it is followed by an 'interpretive analysis' from which broader theoretical readings of field observations may be interpolated. The interpretive reading will iterate back and forth to the descriptive analysis and will depend also on the researcher's theoretical frame of reference and, relatedly, her research aims and objectives which must not be lost sight of, but equally the researcher must remain reflexive and open to other potential insights into and interpretations of what has been observed. This aligns broadly with Van Maanen's (1979) proposal that ethnographic studies in general proceeds from lower- to higher-order conceptions, but with an inevitable 'toing-and-froing'. This should manifest as an inexorable progression from informants" first-order conceptions of "what is going on in the setting” (Van Maanen, 1979: 540), representing 'facts' of an ethnographic investigation, to researchers' second-order conceptions, representing 'theories' researchers use to organize and explain 'facts'. The move from 'informant view' to 'researcher view' is the "key analytic task faced by the ethnographer" (Van Maanen, 1979: 540) in which we, as interpreters of what we have found, mobilize our conceptual and theoretical understandings and give voice to our construal of the deeper structure of the observational data (Langley and Abdallah, 2011).

The above outlines the process in general and broad terms. However, to further concretize these ideas we now offer the illustrative example of the use of Ethnography of Communication in which we proceed: (a) from first-order conceptions of what is going on communicatively as captured in the SPEAKING grid. We term this first-order analysis 'descriptive analysis'; (b) to second-order conceptions as revealed by the researchers' more abstract and theorized readings of the field data. We term this second-order analysis 'interpretive analysis'. In terms of the wellknown 'Gioia method' for qualitative studies (Gioia, Corley \& Hamilton, 2012; Langley \& Abdallah, 2011) this is analogous, but not equivalent, to moving from 'data structure', which presents a "static picture of a dynamic phenomenon" in these cases presented in terms of Hymes' grid, to an account which captures key "emergent concepts" derived from participants' 
experiences and which analyzes "dynamic inter-relationships" (Gioia, et al., 2012: 22). The interpretive phase creates the space not only for traditional induction but also for the possibility of an abductive logic (Agar, 2010; Pierce, 1929). We also borrow from, and concur with, Van Maanen (1979: 541) in emphasizing the fact that drawing-out second-order conceptualizations is "the most difficult yet most interesting goal" of the ethnographer's enterprise. It is in this latter stage where researchers must endeavor to skillfully translate their observations from the field into a compelling interpretive account that offers an interesting and informative narrative whilst remaining alert and reflexive (Cunliffe, 2010).

\section{Illustrative Example: Authority Structures and Communicative Competence in the Enactment of Organizational Power}

This example is based on the first-named author's real-time observations in her role as an account manager in the marketing function of a mineral water company ('WaterCo'). As such, she possessed some of the advantages and disadvantages of a researcher who is also an 'insider' (Gioia \& Chittipeddi, 1991). The scenario was as follows. WaterCo held an important account with multinational supermarket chain 'ShopCo'. Three separate speech events took place over a number of months in at ShopCo's headquarters. Data were recorded in field notes by the firstnamed author both during and immediately after each event. Notes were coded and classified iteratively in terms of various elements of the grid. Analysis and interpretation of the data were discussed and checked with other participants and the co-researcher in order to audit and refine observations. Our research aim, given that organizational power is an important determinant in the outcomes of negotiations (Bloom \& Perry, 2001; Dobson, 2005; Free, 2008), was to use Ethnography of Communication to scrutinize the nature and dynamics of organizational power relationships between a supermarket and a supplier in order to better understand the structuring of cooperative relationships between organizations (Ring \& Van de Ven, 1992). 


\section{Descriptive Analysis}

The speech community we studied comprised WaterCo directors and sellers and ShopCo buyers. Whilst ShopCo was a leading multinational super-market chain with shops all over Europe, WaterCo was a medium, domestic company with a strong local brand. For the last decade WaterCo had been the market leading supplier of natural sparkling mineral water in the face of competition from other national and multinational suppliers. The speech situation was significant for different reasons: for WaterCo it had direct implications for the company's market-leading role, financial performance, strategic marketing, business development, brand awareness, visibility, and product positioning; for ShopCo, it constituted a standard procedure at the beginning of every financial year to decide on those supplier relationships to be sustained or terminated, based on their profitability, and establishing the terms and conditions for doing so. Meetings took place at ShopCo's headquarters. In this context, our aim, given that organizational power is an important determinant in the outcomes of negotiations between retailers and their suppliers (Bloom \& Perry, 2001; Dobson, 2005; Free, 2008), was to use Ethnography of Communication to scrutinize the nature and dynamics of organizational power relationships between the supermarket and its mineral water supplier. Table 4 presents the descriptive analysis of the speech situation and events in terms of the SPEAKING grid; the description and interpretation reported below should be read in conjunction with Table 4 . The table is the refinement and distillation of the field observations rendering them in systematic order in relation to each of the SPEAKING grid's elements and providing a structure for a more abstract interpretation of what was observed in the field, and which now follows.

\section{[TABLE 4 HERE]}

This descriptive analysis has identified clearly-bounded, interrelated, and recurring communicative events which take place in the form of meetings. The proclaimed purpose and the expected outcome of these meetings is the signing of the annual supplier agreement (events 1 and 2), followed by the agreement on the marketing plan (event 3). These communicative events 
(i.e. meetings) take place in rooms at the retailer's headquarters designed specifically for that purpose. The room is one of several of this type in the premises. They are all identical, neighboring each other, and having in the center of the room a large table, with chairs facing each other at opposite sides. There are no windows to the room, but there is a glass partition with the retailer's brand emblazoned on it, the partition allows visibility of the meeting room from the rest of the office. Only one post is pre-assigned and this becomes immediately obvious by the presence of additional resources for the buyer (i.e. telephone, laptop, printed documents, and notepad).

All speakers, i.e. ShopCo's buyers and WaterCo's directors and sellers talk on behalf of their organizations and their stakeholders. They are endowed with legitimacy as representatives of their company, but there are absent addressors in these events (e.g. shareholders, boards of directors, line managers, etc.). There are differing norms of interaction and patterns of communication accorded to specific roles in each of the events. In the first communicative event WaterCo's account manager (along with the other buyer who joins the meeting at a later time) takes the role of the audience, being mostly silent and limited to observing the process of the meeting, speaking when she is addressed. ShopCo's buyer and the WaterCo's commercial director are the main speakers and addressees in this event.

Whilst the account manager's role in the first event is somewhat limited, in the following event we observe that her role is more involved; she plays an active role as a speaker endowed with the power of her position as the sole representative of her company. Finally, in the third event we observe that the newly assigned sales director plays an active role in the speech event, in spite of her limited experience and knowledge in this particular speech community.

These events are characterized by a serious, formal but also polite, respectful, confidential and careful tone intertwined with a more informal interaction, especially at the beginning and the ending of the meetings, evoking a more friendly and relaxed manner. The voice volume and the intonation are noticed to be lower and softer when the speakers addressed their colleagues 
compared to when they are addressing the 'opposite' party. Laughter as a means of (polite or sarcastic) disagreement is also noticeable as a quite usual response. Notably, in the third event, WaterCo's newly-assigned sales' director misinterprets the signaling of the buyer's smile and the occasional interruptions and conceives these behaviors as unfriendly; this interpretation results in her adopting a defensive strategy by focusing mainly on argumentation instead of proceeding to the discussions of the new marketing plan. As a result, the pattern of thematic groupings (message content) changes to include topics irrelevant to the aim of the meeting and the final outcome of the third event turns out to be at variance with its purpose. Having described the communicative event in terms of the SPEAKING grid we now turn to an interpretation of what was observed.

\section{Interpretive Analysis}

Power was a central feature of the social role-relationship that participants brought to the speech (communicative) situation ${ }^{1}$. Power emanated from institutional frameworks but also is a “dynamic, co-constructed product of interaction" (Saville-Troike, 2003: 263). Our purpose was to examine, by way of illustration, how the structure of a communicative (speech) situation (sales negotiation meeting) affected the enactment of organizational power in sales negotiations. By utilising the SPEAKING grid's elements and combining them into theoretically meaningful composites, we were able to show how broader categories pertinent to the research aim, namely authority structure, routinization and ritualization, and communicative competence, are generated.

The authority structure of meetings as communicative situations dispersed power amongst organizational actors through various conscious/explicit/overt and non-conscious/tacit/covert communicative behaviors. Situational particularities (settings and scene) afforded explicit

\footnotetext{
${ }^{1}$ Note: since this is an illustrative example we signal, for explicatory reasons only, significant Hymesian terminologies by the use of italic font.
} 
symbolic indicators of power. The setting of the meeting was ShopCo's headquarters. ShopCo determined the seating arrangement. Additional resources were available for ShopCo's participants. The scene of the 'performance' was a meeting room with ShopCo's brand logo displayed prominently. The standardized meeting room was glass-fronted hence its goings-on were clearly visible beyond the immediate scene into the wider ShopCo setting and to absent participants. These and other attributes of 'situation' signalled not only the formality of the event (key) and its norms, but also ShopCo's power and control, manifesting the situation's authority structure.

Other insights were generated from observing more covert parameters. For example: participants, the espoused 'need' on the part of ShopCo for equal numbers of representatives although there was no requirement for the additional ShopCo participant, the ShopCo Buyer who entered part-way through, the expectation that WaterCo should be represented by a senior manager, and anything less would not be acceptable; speech acts, ShopCo participants' use of paralinguistic features of speaking for example smiles, coughs, and repeated interruptions, were tacit signals of power deployed to strive for or maintain authority. On the other hand unquestioning compliance on the part of WaterCo was witnessed with regard to setting, scene, participants, norms and key. Through the conscious and non-conscious use, and acceptance of, various signallings of authority ShopCo and WaterCo participants were communicatively competent 'knowledgeable agents' (see Giddens, 2013) co-complicit in maintaining established authority structures.

Consideration of the three communicative events also instanced performance of ritual and locally-generated routines reproduced by participants' tacit compliance with authority structures. The act sequence, for example the ritual of being kept waiting in the reception area, and setting of the meeting was replete with conventions and artefacts of routine as in the assigning of places, greetings, and initiatings. To the extent that these routinized micro-conventions had become embedded in the ritualised practices of the community they had, normatively speaking for 
WaterCo at least, become 'core rigidities' with debilitating effects on flexibility, adaptability, subverting WaterCo participants' interests and goals, and militating against the achievement of their intended outcomes.

\section{Theoretical Abstractions}

On the basis of our interpretive analysis we now proceed to show a more abstract interpretation in terms of higher-order categories and theoretical relationships. Ethnography of Communication offered a systematic tool for the identification, capturing, and comparative study of the components of communication. We observed routines and rituals embedded and sustained through various components, and by which organizational power was enacted. Inter-organizational power relationships were instantiated in the dynamic between structure, in this case the authority structure of the communicative situation of sales negotiating, and agency, in this case the communicative competencies of the ShopCo and WaterCo participants (see: Giddens, 1984; Jarzabkowski \& Seidl, 2008; Putnam \& Nicotera, 2009). Participants' conscious and non-conscious communicative behaviours signalled, both explicitly and implicitly, asymmetries of power between ShopCo and WaterCo, for example: 'tight' time allocation; customary act of being kept waiting; battery of resources already on the table for ShopCo; vulnerability of being in the glass-partitioned room emblazoned with ShopCo's logo; the espoused urgency of the 'need' to sign an agreement; numbers of participants on each 'side'; co-opting of additional, but not needed, ShopCo participant; use of prosodic/paralinguistic features to signal perhaps condescension, etc., see Table 4.

The enactment of authority (structure) resulted in participants gaining varying degrees of control over ends through the rules and resources which were the basis of communicative competence (agency) (see Giddens, 2013). Various explicit/implicit and conscious/non-conscious aspects of negotiating behaviours, taken for granted as legitimate practices by participants, "create[d] truth, identity, and security effects for organizational actors" and served as enablers or constrainers of power without being necessarily organized overtly or resisted consciously 
(Jarzabkowski, 2004: 540). Aside and in parallel with these inter-organizational power dynamics (and asymmetries), further intra-organizational dynamics and asymmetries were discerned, for example turn-taking, overt adherence to hierarchy, tacit protocols, and higher-ranking participants taking control. In Event 3 the lack of communicative competence of the Senior Director led to the breakdown of the negotiation, see Table 4 . These findings may be interpreted in terms of a duality of organizational authority structure and actors' communicative competence, the reciprocity of which was enabled and constrained through an appropriation of and acquiescence to organizational routines and rituals, see Figure 1.

\section{[FIGURE 1 HERE]}

Routines and rituals are resources which are called upon by participants in performing social actions. They are part of a "historical accretion" (Barley \& Tolbert, 1997: 99) which defines context which in our case is 'speaking situation', and sets conditions on actions which in our case are 'norms of interaction' and 'communicative competence'. Communicatively competent participants bring to the everyday task of negotiation routines and rituals that are so assimilated into their practical consciousness (Giddens, 2013: xxiii) as to be hardly noticed. In this sense, participants are knowledgeable agents who know 'what to do' or are expected to do, even if they don't always know 'why they are doing it' or appreciate its detrimental consequences.

One outcome of the interplay between the authority structure of the communicative situation (the structure) and the participants' communicative competence (their agency) can be maintenance of power by one group of knowledgeable agents at the expense of another group through the appropriation of routines and rituals by the former and the acquiescence to routines and rituals by the latter. Appropriation and acquiescence are manifest in observed routines and rituals both interorganizationally, for example signalling dominance, and intra-organizationally, for example signalling levels of managerial hierarchy. Agents are co-complicit to the extent that some 
participants appropriate routines and rituals, whilst others acquiesce to routinization and ritualization (see Figure 1).

As well as being theoretically important these dynamics are significant practically, for example awareness of the various components of speech can alert participants to the dysfunctionality of components of speaking as they enact them. Awareness may prompt decoupling of acts from conventions and thereby enable deeper inquiry, learning, and reflexive monitoring of, in this case, communicative competence (see Giddens, 1984, 2013; Hendry \& Seidl, 2003). Hence, in our illustrative example of using Ethnography of Communication we have achieved three things: (1) rendered various components of communication that were manifestations of authority structures as less opaque and therefore potentially more open to scrutiny, critique, and resistance; (2) evidenced the duality of the structure of communicative situations (the routines and rituals of the sales negotiation meeting which were manifestations of implicit authority structures and which were appropriated by ShopCo but equally were acquiesced to by WaterCo) and the agency of communicatively competent participants (ShopCo and WaterCo agents were co-complicit in producing and reproducing the authority structures); (3) forged a connection between organizational discourse research and structuration theory (Giddens, 1984/2013) via the application of Hymes' Ethnography of Communication which is consistent the view that "structure arises from the actions of people, and these actions are shaped by structure" (Brass \& Burkhardt, 1993: 443).

\section{Conclusions}

Organizations and organizing are constituted in-and-through communication (Putnam \& Nicotera, 2009), hence it is important that the study of communicative events should not be reduced to an "afterthought" (Coreen et al., 2011: 1150). Researching organizations as 'communicatively constituted' implies that meanings are tied inextricably to time and space, and communicative events are understood fully only in relation to socio-spatial-temporal factors of the context within, in which they are embedded. As an important branch of sociolinguistics, 
Ethnography of Communication offers organizational researchers an approach for capturing and uncovering the values, strategies and norms that are produced by context and which enable or constrain speaking and communicative competence (Giddens, 2013; Sherry, 1988; Saville-Troike, 2003). Ethnography of Communication facilitates framing and evaluation of speech interactions through comparative and contextual analyses in specific settings, and general features of performance and practice emerging from interpretations of field data may be extrapolated towards building, extending, and testing theories.

We are of the firm view that Ethnography of Communication constitutes an intriguing proposition for organizational discourse researchers, but such a bold claim must be justified. Balogun, Huff and Johnson (2003) proposed criteria for the evaluation of methods for gathering contextually grounded data in organizational research, namely they should: provide contextualized evidence that is simultaneously broad and deep; make effective use of researcher's time; are anchored in organizational realities; and afford useful feedback to informants.

With regard to the viability of our proposals in terms of these criteria we offer the following observations: (1) Ethnography of Communication is contextual by definition, it may be employed longitudinally and comparatively, its remit is broad enough to encompass spatiality and temporality, and it enables data collection and comparison within and between research sites (i.e. systematic collection and analysis of field data via the SPEAKING grid); (2) the grid lends itself to participant observation, and makes effective use of researcher's time because it enables structured collection and organizing of data in various modalities, that is it alerts researchers to various utterances, non-verbal communications, and artefacts; (3) the grid can respond to the thorny issue of identification of units of analysis by being anchored in concrete, clearly-bounded organizational realities by being embedded within the taxonomic framework of speech situations, speech events and speech acts; (4) it is well-placed as a vehicle for offering on-going, researchbased feedback to organization, for example by offering insights into practitioners' communicative competence in relation to their purposes and outcomes. 
Ethnography of Communication also promotes researcher reflexivity because it can sensitize researchers to observations and data that might otherwise have been obscured by their own ethnocentric norms and frames of reference. On the other hand, the filtering or bracketing which the grid exacts comes at a price, therefore ethnographers must be attuned to the partiality of the accounts they create and be reflexive about processes of data collection, analysis and interpretation (Brewer, 2004; Cunliffe, 2010; Hammersley \& Atkinson, 2007). In so far as building research capacity in management and organization studies is concerned, Cunliffe (2010) argued that organizational research and the curriculum of doctoral programs are somewhat impoverished as far as ethnography is concerned. Ethnography of Communication could afford researchers and students the opportunity to engage with ethnographically-oriented inquiry in a systematic and structured manner. For organizational researchers the potential applications of Ethnography of Communication are many and varied, for example communities of practice, cross-cultural communication in MNCs, mergers and acquisitions, expatriate adjustment, strategy-as-practice, Communicative Constitution of Organization, and critical management studies. Ethnography of Communication also lends itself to faculty researching their own communicative competence in management learning and education (MLE) situations.

Researchers who have used Ethnography of Communication in the field tended to refrain from framing generalizable statements and propositions (e.g. Çubukçu, 2007). They have preferred instead to produce systematic and comprehensive 'bottom-up' models of specific social interactions thereby uncovering hidden factors such as lack of disclosure, covert power, class or ritual substrata (Sherry, 1988). Ethnographic research itself has been criticized for a lack of generalizing remit and for the open-endedness if its mode of inquiry. These are limitations. However, models and theories can be a double-edged sword: as well as providing insights they can also force data onto a Procrustean bed. Conversely, "the open-endedness of the ethnographic approach defines its limit but also its force" (Duranti, 1985: 223). In this article we have opted to pursue our descriptions and interpretations beyond the local and contextual to frame more abstract 
and generalizable insights. We hope that in doing so we have been able to demonstrate that Ethnography of Communication is not merely a technique for capturing and organizing facts under the label of 'context' (Blommaert, 2009a) but that it is a paradigm of critical research and reflexivity which has the potential to direct researchers and practitioners to the questions they might and ought to ask, including those that contest taken-for-granted assumptions, challenge received wisdoms, and thereby confront existing orders. 


\section{REFERENCES}

Agar, M. (2010). On the ethnographic part of the mix: A multi-genre tale of the field. Organizational Research Methods, 13(2), 286-303.

Alvesson, M. \& Kärreman, D. (2000a). Varieties of discourse: On the study of organizations through discourse analysis. Human Relations, 53, 1125-1149.

Alvesson, M., \& Kärreman, D. (2000b). Taking the linguistic turn in organizational research challenges, responses, consequences. The Journal of Applied Behavioral Science, 36, 136-158.

Balogun, J., Huff, A.S. \& Johnson, P. (2003). Three responses to the methodological challenges of studying strategizing. Journal of Management Studies, 40, 197-224.

Barley, S. R., \& Tolbert, P. S. (1997). Institutionalization and structuration: Studying the links between action and institution. Organization Studies, 18(1), 93-117.

Belk, R.W., Sherry, J.F., \& Wallendorf, M. (1988). A naturalistic inquiry into buyer and seller behavior at a swap meet. Journal of Consumer Research, 14, 449-470.

Berg, B. (2007). Qualitative research methods for the social sciences. Boston: Allyn and Bacon.

Billig, M. (2001). Discursive, rhetorical and ideological messages. In M. Wetherell, S. Taylor, \& S.J. Yates (Eds.). (2001a). Discourse theory and practice: A reader. London: SAGE, 210221.

Blackledge, A. (2012) In P. Gee \& M. Handford (Eds.) Discourse and power. The Routledge Handbook of Discourse Analysis, pp.616-627. Abingdon: Routledge.

Blackman, D., \& Sadler-Smith, E. (2009). The silent and the silenced in organizational knowing and learning. Management Learning, 40(5), 569-585.

Blommaert, J. (2006) Ethnography as counter-hegemony: Remarks on epistemology and method. In International Literacy Conference, Cape Town.

Blommaert, J. (2009a). Ethnography and democracy. Text and Talk, 29, 257-276.

Blommaert, J. (2009b). On Hymes: Introduction. Text and Talk, 29, 241-243. 
Blommaert, J. \& Dong, J. (2010). Language and movement in space. In N. Coupland (ed.) The Handbook of language and Globalization, pp.366-385. Chichester: Blackwell.

Bloom, P. N., \& Perry, V. G. (2001). Retailer power and supplier welfare: the case of Wal-Mart. Journal of Retailing, 77(3), 379-396.

Brass, D. J., \& Burkhardt, M. E. (1993). Potential power and power use: An investigation of structure and behavior. Academy of Management Journal, 36(3), 441-470.

Brewer, J.D. (2004) Ethnography. In C. Cassell \& G. Symon (Eds.). (2004). Essential guide to qualitative methods in organizational research. London: SAGE, 312-322.

Collins, J. (2009). The place of narrative in human affairs: The implications of Hymes' Amerindian work for understanding text and talk. Text and Talk, 29, 325-345.

Cooren, F., Kuhn, T., Cornellison, J. \& Clark, T. (2011). Communication, organizing and organization: An overview and introduction to the special issue. Organization Studies, 32, 9, 1149-1170.

Covaleski, M. A., Dirsmith, M. W., Heian, J. B., \& Samuel, S. (1998). The calculated and the avowed: Techniques of discipline and struggles over identity in Big Six public accounting firms. Administrative Science Quarterly, 43, 293-327.

Çubukçu, H. (2007). The discourse of betrothal in Turkish culture: an ethnographic perspective. Edebiyat Fakültesi Dergisi, 24(2), 45-62.

Cunliffe, A. L. (2010). Retelling tales of the field in search of organizational ethnography 20 years on. Organizational Research Methods, 13(2), 224-239.

Da Cunha, J. V. (2013). A dramaturgical model of the production of performance data. MIS Quarterly, 37(3), 723-748.

Deetz, S. (2003). Reclaiming the legacy of the linguistic turn. Organization, 10(3), 421-429.

De Saussure, F. (1960). Course in general linguistics. London: Peter Owen.

Dobson, P. W. (2005). Exploiting buyer power: lessons from the British grocery trade. Antitrust Law Journal, 529-562. 
Duranti, A. (1985) Sociocultural dimensions of discourse. In Handbook of discourse analysis, Volume 1, 193-230

Ervin-Tripp, S.M. (2009). Hymes on speech and socialization. Text and Talk, 29, 245-256.

Fairclough, N. (1995). Critical Discourse Analysis: The critical study of language. London: Longman.

Farah, I. (1998). The Ethnography of Communication. In N.H. Hornberger \& P. Corson (Eds.) Encyclopedia of language and education: Volume 8: Research methods in language and education. Dordrecht: Kluwer, 125-127.

Fitch, K. (2001). The ethnography of speaking: Sapir/Whorf, Hymes, and Moerman. In M. Wetherell, S. Taylor \& S.J. Yates (Eds). Discourse theory and practice: A reader. London: SAGE , 57-63.

Free, C. (2008). Walking the talk? Supply chain accounting and trust among UK supermarkets and suppliers. Accounting, Organizations and Society, 33(6), 629-662.

Garfinkel, H. (1974). The origins of the term 'ethno-methodology'. Ethnomethodology, 15, 18.

Garfinkel, H. (Ed.). (1986). Ethnomethodological studies of work. Abingdon: Routledge.

Geertz, C. (1973). The interpretation of cultures. New York: Basic Books.

Gephart, R.P. (1978). Status and degradation in organizational succession: An ethnomethodological approach. Administrative Science Quarterly, 23(4), 553-581.

Giddens, A. (1984/2013). The constitution of society: Outline of structuration theory. Cambridge: Polity Press

Gioia, D. A., Corley, K. G., \& Hamilton, A. L. (2013). Seeking qualitative rigor in inductive research notes on the Gioia methodology. Organizational Research Methods, 16(1), 15-31.

Gioia, D. \& Chittipeddi, K. (1991). Sensemaking and sensegiving in strategic change initiation. Strategic Management Journal, 12, 433-448.

Goodall, H.L. (2010). From tales of the field to tales of the future. Organizational Research Methods, 13(2), 256-267. 
Gronn, P.C. (1988). Talk as the work: The accomplishment of school administration.

Administrative Science Quarterly, 28(1), 1-21.

Gumperz, J.J. \& Hymes, D.H. (1986). Directions in sociolinguistics: The ethnography of communication. Oxford: Basil Blackwell.

Gumperz J. J. \& Levinson S. C. (1996). Rethinking linguistic relativity. Cambridge: CUP.

Gumperz, J. \& Hymes, D. (Eds.) (1972). Directions in sociolinguistics. New York: Holt, Rhinehart \& Winston.

Hammersley, M., \& Atkinson, P. (2007). Ethnography: Principles in practice. Abingdon: Routledge.

Hardy, C., Palmer, I., \& Phillips, N. (2000). Discourse as a strategic resource. Human Relations, $53,1227-1248$.

Heller, M (2003). Discourse and interaction. In Schiffrin, D., Tannen, D., \& Hamilton, H. E. (Eds.). The handbook of discourse analysis. Oxford: Blackwell Publishing, 250-264

Hendry, J., \& Seidl, D. (2003). The structure and significance of strategic episodes. Journal of Management Studies, 40(1), 175-196.

Heritage, J (2001). Goffman, Garfinkel and conversation analysis. In M. Wetherell, S. Taylor \& S.J. Yates (Eds). Discourse theory and practice: A reader. London: SAGE, 47-56.

Hope Hailey, V. \& Balogun, J. (2002). Devising context sensitive approaches to change: The example of Glaxo Wellcome. Long Range Planning, 35, 153-178.

Hornberger, N.H. (2009). Hymes's linguistics and ethnography in education. Text and Talk, 29, $347-358$

Hymes, D.H. (1962). The ethnography of speaking. Anthropology and Human Behavior, $13(53), 11-74$.

Hymes D.H. (1964a). Language in culture and society: A Reader in linguistics and anthropology. New York: Harper \& Row Publishers. 
Hymes D.H. (1964b). Toward ethnographies of communication. American Anthropologist, $66,(2), 1-34$.

Hymes D.H. (1974). Foundations in sociolinguistics: An ethnographic approach. Philadelphia: University of Pennsylvania Press.

Hymes, D. (1972). On communicative competence. In J.B. Pride \& J. Holmes (Eds.)

Sociolinguistics. Harmondsworth: Penguin, 269-285.

Hymes, D. (1986). Models of the interaction of language and social life. In Gumperz, J. \& Hymes, D. (Eds.) (1986). Directions in sociolinguistics. Oxford: Basil Blackwell Ltd., 35-71.

Iedema, R., Long, D., Forsyth, R., \& Lee, B. B. (2006). Visibilizing clinical work: Video ethnography in the contemporary hospital. Health Sociology Review, 15(2), 156-168.

Jakobson, R. (1960). Closing statement: Linguistics and poetics. In Sebeok T. (Ed.) Style in language. Cambridge, MA: MIT Press, 350-377

Jarzabkowski, P., \& Seidl, D. (2008). The role of meetings in the social practice of strategy. Organization Studies, 29(11), 1391-1426.

Jarzabkowski P. (2004). Strategy as practice: Recursiveness, adaptation, and practices-in-use. Organization Studies, 25, 529-560.

Johnstone, B., \& Marcellino, W. (2010). Dell Hymes and the ethnography of communication.

Keating, E. (2001). The ethnography of communication. In P. Atkinson, A. Coffey, S. Delamont, J. Lofland, \& L. Lofland (Eds.) Handbook of ethnography, London: SAGE, 285-301.

Kornberger, M., Justesen, L., \& Mouritsen, J. (2011). When you make manager, we put a big mountain in front of you: An ethnography of managers in a Big 4 accounting firm. Accounting, Organizations and Society, 36(8), 514-533.

Lakoff, G., \& Johnson, M. (1999) Philosophy in the flesh: The embodied mind and its challenge to western thought. New York: Basic Books. 
Langley, A., \& Abdallah, C. (2011). Templates and turns in qualitative studies of strategy and management. In D.D. Bergh \& D.J. Ketchen (Eds.) Research methodology in strategy and management, 6, Bingley, UK: Emerald, 201-235.

Lave, J., \& Wenger, E. (1991). Situated learning: Legitimate peripheral participation. Cambridge: Cambridge University Press.

Lynch, M., \& Peyrot, M. (1992). Introduction: A reader's guide to ethnomethodology. Qualitative Sociology, 15(2), 113-122.

Maybin, J. (2001). Language, struggle and voice: The Bakhtin/Volosinov writings. In M. Wetherell, S. Taylor, \& S.J. Yates (Eds.). (2001a). Discourse theory and practice: A reader. London: SAGE, 64-71.

Maybin, J. \& Tusting K. (2011) Linguistic ethnography. In J. Simpson (Ed.) The Routledge Handbook of Applied Linguistics, pp.515-528. Abingdon: Routledge.

McNary, L. D. (2003). The term 'win-win' in conflict management: A classic case of misuse and overuse. Journal of Business Communication, 40(2), 144-159.

Phillips, N. \& Oswick, C. (2012). Organizational discourse: Domains, debates and directions. Academy of Management Annals, 6(1), 435-481.

Phillips, N., Sewell, G., \& Jaynes, S. (2008). Applying critical discourse analysis in strategic management research. Organizational Research Methods, 11, 770-789.

Pollner, M. \& Emerson, R.M. (2001) Ethnomethodology and ethnography. In P. Atkinson et al. (Eds.) The SAGE Handbook of Ethnography, pp.118-135. London SAGE.

Putnam, L.L. \& Nicotera, A.M. (2009). Building theories of organization: The consultative role of communication. New York: Routledge.

Rampton, B. (2009). Dell Hymes' visions of enquiry. Text and Talk, 29, 359-369.

Rampton, B. Maybin, J. \& Roberts, C. (2014). Methodological foundations in linguistic ethnography. Working Papers in Urban Language \& Literacies (Paper 125), King's College London 
Ring, P. S., \& Van de Ven, A. H. (1992). Structuring cooperative relationships between organizations. Strategic Management Journal, 13(7), 483-498.

Sacks, H. (1992). Lectures on conversation (Ed. G. Jefferson). Oxford: Blackwell.

Samra-Fredericks, D. (2003). Strategizing as lived experience and strategizing: Everyday efforts to shape strategic direction. Journal of Management Studies, 40, 141-174.

Sarangi, S. (2009). Editorial: Hymes, text and talk. Text \& Talk 29(3), 239-240.

Saville-Troike M. (2003). The ethnography of communication: An introduction. Oxford: Blackwell.

Scott, J. \& Marshall, G. (2005). Oxford dictionary of sociology. Oxford: OUP.

Sherry Jr, J. F. (1988). Market pitching and the ethnography of speaking. Advances in Consumer Research, 15, 543-547.

Sherzer, J. (1987). Discourse-centered approach to language and culture. American Anthropologist, 89(2), 295-309.

Schiffrin, D., Tannen, D., \& Hamilton, H. E. (Eds.). (2003). The handbook of discourse analysis. Oxford: Blackwell.

Smart, G. (2012) Discourse-oriented ethnography. In P. Gee \& M. Handford (Eds.) Discourse and power. The Routledge Handbook of Discourse Analysis, pp.147-159. Abingdon: Routledge.

Taylor, S. (2001) Evaluating and applying discourse analytic research. In Wetherell, M., Taylor, S., \& Yates, S. (Eds) Discourse as data: A guide to analysis. London: SAGE, 311-330.

Tsoukas, H., \& Vladimirou, E. (2001). What is organizational knowledge? Journal of Management Studies, 38(7), 973-993.

Van Maanen, J. (1979). The fact of fiction in organizational ethnography. Administrative Science Quarterly, 24, 539-550

Van Maanen, J. (1988). Tales of the field. Chicago University of Chicago Press. 
Van Maanen, J. (2006). Ethnography then and now. Qualitative Research in Organization and Management, 1(1), 13-21.

Wenger, E. (1998). Communities of practice: Learning, meaning and participation. Cambridge: Cambridge University Press.

Wetherell, M., Taylor, S., \& Yates, S. (2001b). Discourse as data: A guide to analysis. London: SAGE.

Wetherell, M., Taylor, S., \& Yates, S. J. (Eds.). (2001a). Discourse theory and practice: A reader. London: SAGE.

Wodak, R., Kwon, W., \& Clarke, I. (2011). 'Getting people on board': Discursive leadership for consensus building in team meetings. Discourse \& Society, 22(5), 592-644. 
Figure 1. The duality of authority structures and communicative competence in the enactment of organizational power in sales negotiations

\section{Produces and reproduces routines and rituals}

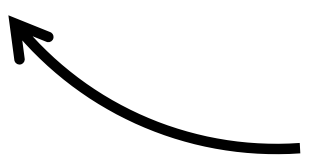

Authority structure

of communicative situation

Acquiescence

and

Appropriation

Agency of actors'

communicative

competence
Enables and constrains through routinization and ritualization

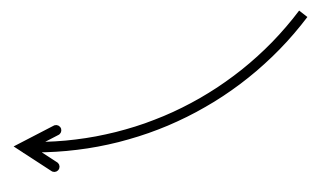


Table 1. Selected approaches for the study of discourse

\begin{tabular}{ll}
\hline Approach & Description \\
\hline Conversation Analysis / & Interactional linguistics is a broad term denoting variety of \\
Interactional Linguistics & approaches concerned with use of language in social interaction; \\
& sociological focus on social behaviors and practices that constitute \\
& language use in social context (e.g. Goffman); linguistic focus on \\
& relationship between social context and structure and function of \\
& language (e.g. Sacks), includes conversation analysis (Yates, 2001). \\
& Semiotic dimensions of power, injustice, abuse, and political, \\
Critical Discourse & economic and cultural change in society; discourse seen as form of \\
Analysis (CDA) & social practice; dialectic between discursive events and social \\
& structures; discourse is socially constitutive and socially shaped; \\
& aims to make visible the opaque aspects of discourse-as-social- \\
& practice; engaged and committed rather than objective and \\
dispassionate; topic-driven rather than methodologically-driven. & \\
& Emphasizes anthropological and ethnographic aspects of the \\
relationships between language and culture; study of speech \\
communities and social basis of communicative competence (cf. \\
linguistic competence) (Wetherell et al., 2001). \\
The study of people's methods for creating social order including \\
language use and the unstated assumptions which govern its use \\
and interpretation (Saville-Troike, 2003). Aim is to understand the \\
methods individuals use to make ordinary, everyday, practical \\
sociological reasoning analyzable (Garfinkel, 1974). \\
Ethnomethodology is not a single coherent approach; instead it \\
relies to varying degrees on contributions from various sub-fields \\
including social psychology and interpretive sociology (Lynch \& \\
Peyrot, 1992).
\end{tabular}


Table 2. Hymes' SPEAKING grid dimensions and sub-components (adapted from Hymes, 1974: 55-62; Saville-Troike, 2003: 95-124)

\begin{tabular}{ll}
\hline Dimension & Sub-components \\
\hline Situation (S) & Setting \\
& Scene \\
\hline Participants (P) & $\begin{array}{l}\text { Speaker, sender; Addressor; Hearer, receiver, audience; Addressee } \\
\text { (present or absent) }\end{array}$ \\
\hline Ends (E) & $\begin{array}{l}\text { Purpose - goals } \\
\text { Purposes - outcomes }\end{array}$ \\
\hline Act sequence (A) & Sequential organization of speech acts \\
& Message form \\
& Message content \\
\hline Key (K) & Keys \\
\hline Instrumentalities & Medium of transmission of speech \\
(I) & Forms of speech and speech style \\
\hline Norms (N) & Rules of interaction: rules governing speaking \\
& Norms of interpretation: rules governing cultural belief systems \\
\hline Genre (G) & Genres \\
\hline
\end{tabular}


Table 3. Guidelines for data acquisition (Adapted from Saville-Troike, 2003: 95-124)

\begin{tabular}{|c|c|}
\hline Description & Sample questions \\
\hline Setting & $\begin{array}{l}\text { What does the setting look like, what is the time of } \\
\text { day, what is the physical arrangement of artefacts? } \\
\text { How do participants organize themselves } \\
\text { spatially/temporally? }\end{array}$ \\
\hline Scene & $\begin{array}{l}\text { What is the cultural definition/significance of the } \\
\text { occasion? }\end{array}$ \\
\hline $\begin{array}{l}\text { Participants: Speaker, sender; } \\
\text { Addressor; Hearer, receiver, } \\
\text { audience; Addressee (present or } \\
\text { absent) }\end{array}$ & $\begin{array}{l}\text { Who (present or absent) is taking part in the event } \\
\text { (age, gender, ethnicity, etc.)? } \\
\text { What is the observed/actual hierarchy of authority? } \\
\text { What are participants' roles/responsibilities, } \\
\text { rights/obligations, attitudes/expectations, etc.? }\end{array}$ \\
\hline \multicolumn{2}{|r|}{ 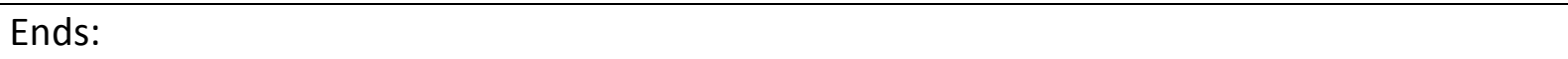 } \\
\hline Purpose - goals & $\begin{array}{l}\text { What is the event about and why is it happening? } \\
\text { What goals are participants endeavoring to achieve? }\end{array}$ \\
\hline Purposes - outcomes & What outcomes did the participants actually achieve? \\
\hline \multicolumn{2}{|l|}{ Act: } \\
\hline $\begin{array}{l}\text { Sequential organization of speech } \\
\text { acts }\end{array}$ & $\begin{array}{l}\text { Is there a sequential ordering of speech acts, if so what } \\
\text { is it? }\end{array}$ \\
\hline Message form & $\begin{array}{l}\text { What channels (vocal, non-vocal) and codes } \\
\text { (verbal/non-verbal) are in use? }\end{array}$ \\
\hline Message content & What is the message content (of a given speech act) \\
\hline Key & $\begin{array}{l}\text { What is the tone, manner, or spirit in which the speech } \\
\text { act is performed? }\end{array}$ \\
\hline \multicolumn{2}{|l|}{ Instrumentalities: } \\
\hline Medium of transmission of speech & What linguistic resources are available? \\
\hline Forms of speech and speech style & What are the styles of speaking? \\
\hline \multicolumn{2}{|l|}{ Norms: } \\
\hline $\begin{array}{l}\text { Rules of interaction: rules } \\
\text { governing speaking }\end{array}$ & What are the rules that govern speaking for the event? \\
\hline $\begin{array}{l}\text { Norms of interpretation: rules } \\
\text { governing cultural belief systems }\end{array}$ & $\begin{array}{l}\text { What are the standards of speech, how are breaches } \\
\text { evaluated, what are the sanctions for doing so? }\end{array}$ \\
\hline Genres & What is the type of event? \\
\hline
\end{tabular}


Table 4. Descriptive analysis of strategic marketing negotiation

\begin{tabular}{|c|c|c|c|}
\hline & Event 1 & Event 2 & Event 3 \\
\hline \multirow{4}{*}{ 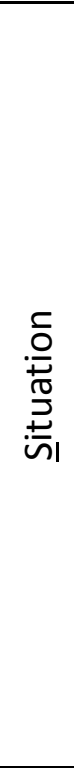 } & \multicolumn{3}{|c|}{$\begin{array}{l}\text { The setting is a meeting room at the ShopCo's headquarters. There are several } \\
\text { identical meeting rooms, lined one next to the other. }\end{array}$} \\
\hline & \multicolumn{3}{|c|}{$\begin{array}{l}\text { In the centre of the room there is a large table, with chairs on opposite sides of the } \\
\text { table. One seat is pre-assigned (evidenced by the presence of a laptop computer, } \\
\text { printed documents, notebook, and telephone landline). }\end{array}$} \\
\hline & \multicolumn{3}{|c|}{$\begin{array}{l}\text { There are no windows to the room but there is a wall-to-ceiling glass partition } \\
\text { engraved with the retailer's brand that allows participants to see out and to be seen } \\
\text { by the ShopCo employees who pass by the room. }\end{array}$} \\
\hline & \multicolumn{3}{|c|}{$\begin{array}{l}\text { These meetings take place at the beginning of the year and last around an hour and a } \\
\text { half with a tight schedule and time allocation at the behest of ShopCo due to other } \\
\text { appointments and commitments. The meeting starts as soon as the buyer (ShopCo } \\
\text { participant) goes to the reception, offers a salutation and calls-in the visitors who have } \\
\text { been waiting there along with other companies' representatives, as part of a common } \\
\text { procedure followed in these occasions. }\end{array}$} \\
\hline \multirow{6}{*}{ 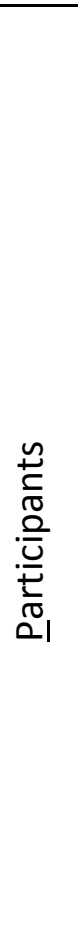 } & $\begin{array}{l}\text { Participants: initially, three; but } \\
\text { finally, four: }\end{array}$ & $\begin{array}{l}\text { Participants: Two } \\
\text { (speakers and }\end{array}$ & $\begin{array}{l}\text { Participants: initially, three; } \\
\text { but finally, four. }\end{array}$ \\
\hline & $\begin{array}{l}\text { ShopCo's Senior Buyer (male) } \\
\text { (SB); } \\
\text { WaterCo's Commercial Director } \\
\text { (male) (CD) and the Account } \\
\text { Manager (female) (AM). }\end{array}$ & $\begin{array}{l}\text { addressees): the SB } \\
\text { and the AM. }\end{array}$ & $\begin{array}{l}\text { ShopCo's SB and WaterCo's } \\
\text { AM and the newly assigned } \\
\text { Sales Director (female) } \\
\text { (SD). } \\
\text { During the event ShopCo's }\end{array}$ \\
\hline & $\begin{array}{l}\text { Shortly after the start of the } \\
\text { meeting another ShopCo Buyer } \\
\text { (male) (B) enters the room and } \\
\text { sits next to his senior colleague. }\end{array}$ & & $\begin{array}{l}\text { B joins the meeting. } \\
\text { Speakers: SB, SD, AM } \\
\text { Addressees: SB, SD, AM }\end{array}$ \\
\hline & Speakers: SB and CD & & \\
\hline & Addressees: SB, CD, AM, B & & \\
\hline & $\begin{array}{l}\text { Audience: } B \text { and } A M \text { do not take } \\
\text { a proactive role in the event; } \\
\text { they participate when being } \\
\text { addressed. }\end{array}$ & & \\
\hline
\end{tabular}


Proclaimed purpose (and expected outcome): signing of the annual agreement for supplying WaterCo's mineral water products to ShopCo (Events $1 \& 2$ ) and setting the specifications of the marketing and promotional plan (Event 3 ).

The goal for each company is to reach an agreement on the best possible terms for their respective organizations.

The SB also makes clear to WaterCo's representatives that he is restricted by ShopCo deadlines and consequently an inferred aim for him would be to sign this agreement soon.

The first two meetings, viewed as a single discontinuous communicative event, reached the proclaimed purpose with the signing of the new agreement (the purpose 气 coincided with the outcome).

II In the 3rd event the participants did not reach the necessary stage in the discussions, and another meeting had to be rescheduled.

\begin{tabular}{|c|c|c|}
\hline $\begin{array}{l}\text { Additional aims for WaterCo: } \\
\text { CD: to introduce the AM to } \\
\text { ShopCo's SB and to provide the } \\
\text { required training. } \\
\text { AM: to develop her } \\
\text { understanding of the } \\
\text { negotiations and the required } \\
\text { managerial competencies. }\end{array}$ & $\begin{array}{l}\text { The AM's additional } \\
\text { aim is also to prove } \\
\text { her competency in } \\
\text { her role. }\end{array}$ & $\begin{array}{l}\text { Additional aim for } \\
\text { WaterCo: } \\
\text { AM: to introduce the SD } \\
\text { and to show her the ways } \\
\text { in which they collaborate } \\
\text { with this account. } \\
\text { SD: to advocate her role, } \\
\text { demonstrating presence } \\
\text { and capability. }\end{array}$ \\
\hline
\end{tabular}

Message form: verbal interaction and nonverbal interactions, comprising both vocal features, such as laughter, and non-vocal features, such as facial expressions, head nods, silence and hand movements.

The message content of Events 1 and 2 had similar patterns of thematic groupings including: initial greeting, offering of drinks, discussion on general issues, introduction to the topic, assessment of the previous year's business and financial performance, forecasting for the year ahead, discussion on the competition, presentation of sales

$\underset{\&}{*}$ targets, negotiation on the terms of the contract, agreement on the course of action to be followed, setting of new appointment, conclusion of discussion with informal conversations.

Event 3 however, comprised only the initial speech acts (greetings and offering of drinks), followed by the introduction of the SD and a general discussion on her work, the declaration of WaterCo's anticipations in regards to the cooperation, an assessment of the two companies collaboration in respect to the problems and challenges faced in the past, the arrangement of a new meeting. 
Serious, formal, polite, respectful, confidential and careful tone, intertwined with a more informal tone of interaction especially at the beginning and the ending of the events inducing a more friendly and relaxed manner. Vocal volume and intonation were lower and softer when the speakers were addressing colleagues compared to ऐ। when they were addressing the opposite party. Laughter was used as a means of signalling (polite or sarcastic) disagreement, and was noticed to be a frequent communicative strategy.

In Event 3, according to the SD, the key was also ironic and rude (based on the signalling of the SB's smile and the occasional interruptions to her speaking).

The medium (channel) of transmission of speech is face-to-face oral, written and visual communication in the form of hard copies (documents, sales charts, and diagrams). The speech style characterized by an occasional use of certain jargon and the use of technical commercial and financial terminology, such as 'P\&L' (profit and loss) and 'cumule turnover' (cumulative turnover).

Norms of interaction: formal dressing, standardised procedures, timeline, formality when discussing the main topics, indirect expression of disagreement, turn-taking governed equally by the two sides by the higher-ranked participants, tacit protocol on who takes the lead in speaking on behalf of each company and the hushed tone and passive role of the other(s).

ह Norms of interpretation: the specific timeline dictated by the retailer, the particular $\xi$ allocation of seats in the room, the need for an equal number of representatives from $z \mid$ each company from the part of the retailer (with the buyer asking for a colleague to participate when needed), the need for a higher ranked individual to be present in the meeting on behalf of the ShopCo, tactics of interruptions and smiling when disagreeing with the opposite side performed by specific participants (i.e. higher status), the availability of additional equipment to the buyer even though that it was not needed. 


\section{ENDNOTES}

${ }^{1}$ The American tradition is seen by many scholars as beginning with the work of Franz Boas (18581942), a field researcher of Native American languages considered to be a primary shaper of American linguistic anthropology (Hymes, 1964). In Europe (more particularly England) the Polish-born Bronisław Malinowski (1884-1942), founding figure of Functionalism, was one of the few anthropologists of his time to have an abiding interest in language itself (regarding language as a 'mode of action' which receives its meaning from its relation to the situational context, Langendoen, 1968). In his foundational work at the start of the $20^{\text {th }}$ century he linked ethnography and linguistics, despite the fact that an interest in language and linguistics was only sporadic in British social anthropology (Rampton, 2007).

${ }^{2}$ The relationship between the grammatical categories of the language a person speaks and how the person perceives the world and behaves in it, as well as the way that language can shape our thoughts and influence our acts constitute the so-called 'Sapir-Whorf hypothesis' or the principle of linguistic relativity (Whorf, 1956). Although the hypothesis has proven to be foundational, some consider the term 'Sapir-Whorf hypothesis' itself to be a misnomer.

${ }^{3} \mathrm{As}$ an interdisciplinary field, sociolinguistics is sometimes associated with a number of similar terms that are not always synonyms, such as linguistic anthropology, ethno-linguistics and anthropological linguistics (see: Duranti, 1997).

${ }^{4}$ Ferdinand de Saussure, the Swiss professor whose lectures on general linguistics - published after his death by his students - set the direction of European linguistic analysis from the 1920's onwards. Considered to be the "father of structuralism on the European continent" (Hymes, 1964: 5), Saussure described language as "a system of signs that express ideas" (De Saussure, 1960: 65) attaching for the first time the term 'sign' to the definition of language and concerning himself with the correspondence between words and ideas. Saussure put a great emphasis on the fact that language constitutes a form which represents the duality between word and concept and tried to show how social forces change the language networks over time. He explained that if we consider language in time, without the community of speakers, we probably would notice no change and, thus, time would not influence language. Conversely, if we considered the community of speakers without considering time, it would not be possible to observe the social forces that influence language (De Saussure, 1960).

${ }^{5}$ For a critique of Chomsky's account of linguistic competence see: Habermas, J. (1970). Towards a theory of communicative competence, Inquiry, 13: 360-375.

${ }^{6}$ Hymes' biography may help to understand this positioning: he was stationed as GI in the Far East in World War II and saw Hiroshima shortly after the destruction wreaked by the dropping of the atomic bomb. Blommaert (2009a) maintains this "turned him into someone whose main concerns were peace, equality, and solidarity" (pp.257-258). For Hymes ethnography was part of a left-leaning political vision (Blommaert, 2009a).

${ }^{7}$ Hymes (1974) noted, perhaps mischievously, that a French re-labelling of the mnemonic was possible (PARLANT: participants, actes, raison, locale, agents, norms, toltypes) and thereby drew attention to the fact that "the code word is not wholly ethnocentric" (p.62). 